\title{
The Case of GSV Transient (Evening, Orthodependent) Reflux in a Hip Going into the Tributary in Woman with Reticular Varicose Veins (C1s)
}

\section{Yu T Tsukanov* and AI Nikolaichuk}

Department of Surgical Diseases, Omsk State Medical University, Omsk, Russia

"Corresponding author: Yu T Tsukanov, Department of Surgical Diseases, Omsk State Medical University, Omsk, Russia, Tel: +73812360762; E-mail: yutsoukanov@mail.ru

Rec date: August 12, 2015; Acc date: September 8, 2015; Pub date: September 15, 2015

Copyright: ( 2015 Tsukanov YT. This is an open-access article distributed under the terms of the Creative Commons Attribution License, which permits unrestricted use, distribution, and reproduction in any medium, provided the original author and source are credited.

\section{Introduction}

The modern classification CEAP includes six groups of disorders [1]. They are called as "classes", not as "stages". The reason is that between the classes $\mathrm{C} 0-1$, on the one hand, and the classes $\mathrm{C} 2$ and higher, on the other, there considered to be a gap. The following research is useful to understand the significance of transient refluxes in hypodermic varicose development in mild CVD forms.

\section{Presentation}

A 41-year-old woman presents with complaints of aesthetic defect of legs. She works as a shop assistant in a store. Her working day in a standing position lasts up to 10 hours. She has been pregnant twice and now has two children. She notes the family history of varicose veins from mother's side. While evening examination at 6 p.m. (after her working day) the skin is of normal colour and there is an artery pulsation in all pulse points. Both hip superficies contain spider veins and single reticular varicose. She states leg heaviness and tiredness, aching in the internal hip surface of the right leg in its lower part at the end of the working day, night cramps. The results of DS after «a day orthostatic loading test» (shortly DOL-test) showed that the diameter of GSV in the right area of saphenofemoral junction is $6.5 \mathrm{~mm}$ which is the same for the area between the middle and the lower third of the hip. There is a $12 \mathrm{~cm}$ reflux in the middle third of the hip going into the extended hypodermic tributary with commissural GSV valve insufficiency in the area between the middle and the lower third (Figure 1).

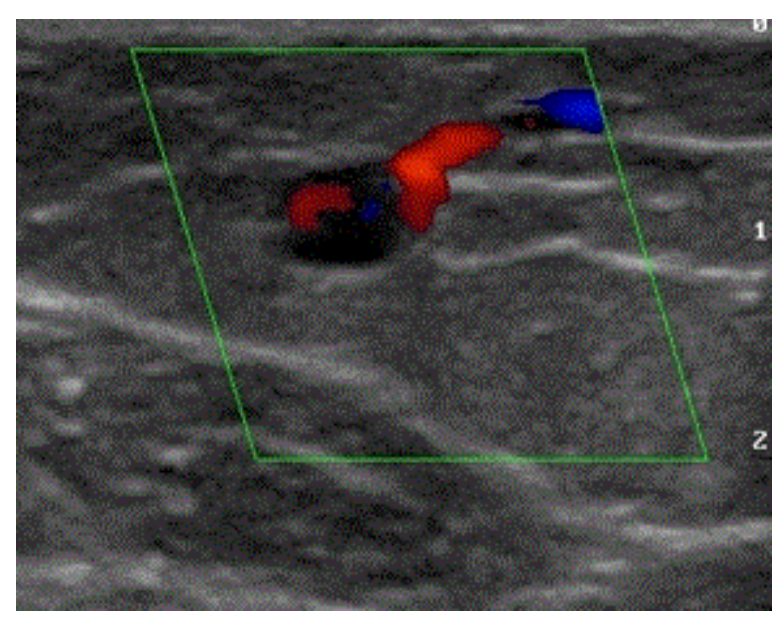

Figure 1: Evening DS.
A 41-year-old woman after a day orthostatic loading (10 working hours in a standing position). GSV cross section in the middle third of the hip in the valve area, vessel diameter is $6.5 \mathrm{~mm}$. GSV reflux goes into the extended hypodermic tributary.

The patient denies any complaints during the second examination made at 9 a.m. after a good night's rest. The results of DS showed that the diameter of GSV in the area of saphenofemoral junction is $5.5 \mathrm{~mm}$ in the area of compromised valve is $4.0 \mathrm{~mm}$. There is no GSV reflux, especially in the area of interest. The compromised tributary is not determined (Figure 2).

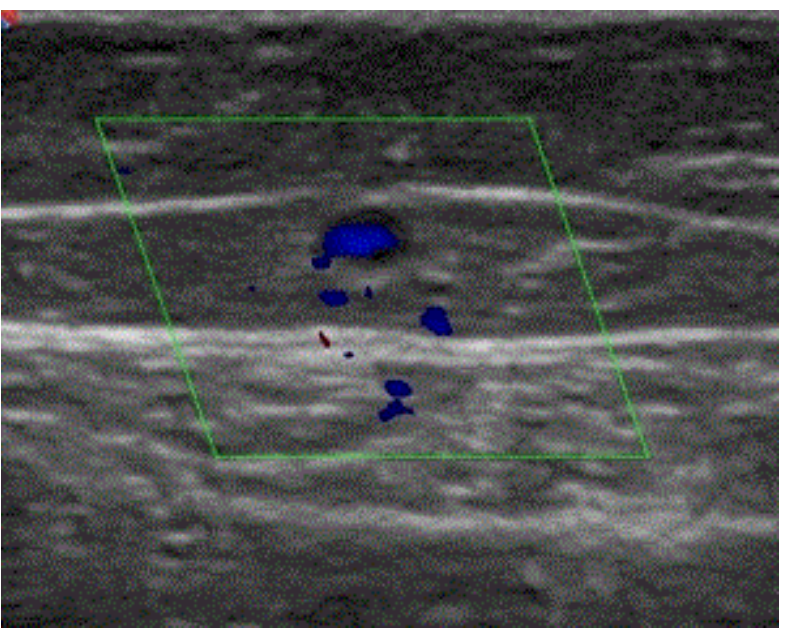

Figure 2: Morning DS.

A 41-year-old woman after a good night's rest (10 working hours in a standing position). GSV cross section in the middle third of the hip in the valve area, vessel diameter is $5.5 \mathrm{~mm}$. There is no GSV reflux. Compromised tributary is not determined.

\section{Discussion}

The present examination of a woman with C1s when the transitory reflux goes into the tributary in the evening and does not occur in the morning after a good night's rest makes a hypothesis of transitory refluxes being a stage for the following hypodermic varicose development even more tenable.

It is important to mention that revealing of such a feature was possible due to the original method of DOL-test, the advantages of which are described below. Firstly, day orthostatic loading causes classical venous disorders that do not occur independently. Secondly, 
Citation: Tsukanov YT, Nikolaichuk Al (2015) The Case of GSV Transient (Evening, Orthodependent) Reflux in a Hip Going into the Tributary in Woman with Reticular Varicose Veins (C1s). J Vasc Med Surg 3: 219. doi:10.4172/2329-6925.1000219

Page 2 of 2

DOL-test is a natural form of examination, which does not break patient's living conditions and correspond to the peculiarities of a human vital activity. Thirdly, DOL-test gives an opportunity to evaluate the functional reserve of individual viscoelastic properties of the venous wall of a particular patient and to determine his validity in those areas of life connected with physical activity.

As a matter of fact, C0s and C1s (according CEAP) are the most harmless variants of disorders! However, one part of such patients have GSV evening reflux [2]. It's a transient (evening, orthodependent) reflux because it's absent in the morning. If due to hard living conditions it repeats every day, it is easy to assume that eventually it will become permanent and lead to varicose dilatation. And it's important, that the first experience of treating transient reflax with venoaktiv drug is positive [2].

This hypothesis is also based on a well-known fact that in humans the incidence of varicosities increases with age $[1,3]$. Thus, there remains only one question: why have not we seen it before?! Actually, there is the answer! This transition lasts for many years and is not always obvious. Of course, this is our working hypothesis. Of course, it needs further investigations. However, this hypothesis explains a possible connection between these different classes.

\section{References}

1. Eklof B, Rutherford RB, Bergan JJ, (2004) Revision of the CEAP classification for chronic venous disorders: consensus statement. J Vase Surg 40: 1248-1252.

2. Tsoukanov Yu T, Tsoukanov A Yu, Nikolaychuk A (2015) Great saphenous vein transitory reflux in patients with symptoms related to chronic venous disorders, but without visible signs (C0s), and its correction with MPFF treatment. Phlebolymphology 22: 18-24.

3. Schultz-Ehrenburg U, Weindorf N, Matthes U, Hirche H (1992) An epidemiologic study of the pathogenesis of varices. The Bochum study IIII [in French]. Phlébologie 45: 497-500. 